\title{
The mechanical and biological studies of calcium phosphate cement-fibrin glue for bone reconstruction of rabbit femoral defects
}

This article was published in the following Dove Press journal:

International Journal of Nanomedicine

29 March 2013

Number of times this article has been viewed

\author{
Jingjing Dongl,* \\ Geng Cui ${ }^{2} * *$ \\ Long $\mathrm{Bi}^{1}$,* \\ Jie $\mathrm{Li}^{3}$ \\ Wei Lei'
}

'Institute of Orthopedics, Xijing Hospital, Fourth Military Medical University, Xi'an, Shaanxi, People's Republic of China; ${ }^{2}$ Institute of Orthopedics, General Hospital of PLA, Beijing, People's Republic of China; ${ }^{3}$ Institute of Gynecology and Obstetrics, General Hospital of PLA, Beijing, People's

Republic of China

*These authors contributed equally to this work
Correspondence: Wei Lei Institute of Orthopedics, Xijing Hospital, Fourth Military Medical University, Xi'an, Shaanxi 7I0032, People's Republic of China Tel +8602981901696 Fax +86029847 710 II Email fmmuleiwei@।26.com

\begin{abstract}
In order to improve the mechanical and biological properties of calcium phosphate cement (CPC, nanometer-biomaterial) for bone reconstruction in the rabbit femoral defect model, fibrin glue (FG, the natural product, purified from the blood) was introduced at three different ratios. The $\mathrm{CPC}$ powder and the FG solution were mixed, respectively, at the powder/liquid $(\mathrm{P} / \mathrm{L})$ ratios $(\mathrm{g} / \mathrm{mL})$ of $1: 1,3: 1$, and $5: 1(\mathrm{~g} / \mathrm{mL})$, and pure CPC was used as a control. After being implanted into the femoral defect in rabbit, the healing process was evaluated by micro-computed tomography scan, biomechanical testing, and histological examination. By micro-computed tomography analysis, the $\mathrm{P} / \mathrm{L}$ ratio of $1: 1(\mathrm{~g} / \mathrm{mL})$ group indicated the largest quantity of new bone formation at 4 weeks, 8 weeks, and 12 weeks after implantation, respectively. Bone volume per trabecular volume of the 1:1 group was highest in the four groups, which was $1.45 \% \pm 0.42 \%$, $7.35 \% \pm 1.45 \%$, and $29.10 \% \pm 1.67 \%$ at 4 weeks, 8 weeks, and 12 weeks after the operation, respectively. In the biomechanical tests, the compressive strength and the elastic modulus of the three CPC-FG groups were much higher than those of the pure CPC group at the determined time point $(P<0.05)$. The histological evaluation also showed the best osseointegration in the 1:1 group at 4 weeks, 8 weeks, and 12 weeks after the operation, respectively. In the 1:1 group, the bone grew into the pore of the cement in the laminar arrangement and connected with the cement tightly at the 12 th week after the operation. This present study indicated that the CPC-FG composite at the $\mathrm{P} / \mathrm{L}$ ratio of $1: 1(\mathrm{~g} / \mathrm{mL})$ stimulated bone regeneration better than any other designed group, which suggested that $\mathrm{CPC}-\mathrm{FG}$ at the $\mathrm{P} / \mathrm{L}$ ratio of $1: 1$ has significant potential as the bioactive material for the treatment of bone defects.
\end{abstract}

Keywords: calcium phosphate cements, fibrin glue, bone reconstruction, micro-CT, biomechanical testing, histological examination

\section{Introduction}

The reconstruction of segmental bone defects, which are caused by trauma, cancer, and metabolic disorders, remains the major challenge in orthopedics. Although autogenous bone grafts are still regarded as the golden standard for the treatment of bone defects, insufficient availability of grafting tissues and postoperative donor-site morbidity limit the application of bone autografting. ${ }^{1-3}$ Furthermore, the application of bone allograft is also restricted by its antigenicity and the risk of disease transmission. ${ }^{4}$ As a result, it is required to produce the ideal materials that could overcome the disadvantages of the grafting tissues.

Synthetic material is the promising bone substitute, which could offer unlimited availability without causing donor-site morbidity and disease transmission. Calcium phosphate, such as hydroxyapatite (HA), $\beta$-tricalcium phosphate, and calcium 
phosphate cements (CPC) are well researched, widely used, and have been proven to have good biocompatibility and bioactivity. ${ }^{5-7}$ Moreover, they are all resorbable and noninflammatory, without causing immunological responses and having excellent osteoconductive ability. Nevertheless, both HA and $\beta$-tricalcium phosphate are solid and prefabricated materials with a certain shape, which need to be remodeled to fit the shape of the defect in the clinic. ${ }^{8}$

In contrast, $\mathrm{CPC}$ is a mixture at certain determined powder to liquid $(\mathrm{P} / \mathrm{L})$ ratios and can form the remodeled and injectable paste, which facilitates the operative procedure and fills the irregular bone defect easily. CPC was firstly reported by Chow and Brown. ${ }^{9}$ Since then, CPC has been investigated by many material scientists, and the first marketed product (BoneSource $^{\circledR}$, Stryker Instruments, Kalamazoo, MI, USA) was developed in the 1990s. Nowadays, a number of types of CPCs are commercially available, and most of them are the nanometer product. In addition to the commonness of the calcium phosphate materials, CPC has two main advantages. Firstly, CPC is obtained by mixing one or several reactive calcium phosphate powders with an aqueous solution to form the solid calcium phosphate at room temperature. Secondly, this cement could be easily shaped to fill irregular bone defects and cavities. However, it still has some disadvantages, especially with respect to its mechanical properties. $\mathrm{CPC}$ is the brittle ceramic and the $0.2 \%$ deformation strain could cause shape failure. ${ }^{10}$ It is desirable to increase the mechanical properties of CPC and therefore make it bear larger deformation strains.

In order to improve the mechanical properties of $\mathrm{CPC}$, other injectable materials such as chitosan, gelatin, and collagen have been introduced into this material. ${ }^{11,12}$ Fibrin glue (FG) is a kind of elastomeric, biocompatible material with sufficient adhesive strength, which has been approved by the Chinese State Food and Drug Administration. Because of its adhesive properties, hemostatic activity, and wound healing process, this biological adhesive is widely used in surgery for repairing tissue damage and blood vessel injury. Some material scientists found that FG could stimulate bone formation in a mouse study. ${ }^{13}$ In a previous study, FG-coated calcium phosphate and glass ceramics were implanted into the extraskeletal site of male Swiss albino mice. The new bone formation was observed in the FG-coated groups. Some additional studies supported the standpoint that the FG stimulates bone formation. ${ }^{14,15}$ Different sizes and different ratios of composites always have different properties; ${ }^{16}$ it is unclear whether a different ratio of $\mathrm{CPC}$ and FG has different properties for bone reconstruction.
In this study, we prepared the injectable composites by mixing $\mathrm{CPC}$ and $\mathrm{FG}$ at different $\mathrm{P} / \mathrm{L}$ ratios and investigated the optimal $\mathrm{P} / \mathrm{L}$ ratio between $\mathrm{CPC}$ and $\mathrm{FG}$ for repairing bone defects in vivo. We hypothesized that: (1) CPC powder and FG, mixed at the optimal ratio, could realize a good match between material degradation and new bone formation; and (2) the introduction of FG could improve the mechanical properties of CPC and improve osteoconduction for new bone formation.

\section{Materials and methods Preparation of CPC-FG composites}

The CPC powder (the nanometer product; Shanghai Rebone Biomaterials Co, Ltd, Shanghai, People's Republic of China) and FG (Guangzhou Bioseal Biotech Co, Ltd, Guangzhou, People's Republic of China) used in this study were approved by the Chinese State Food and Drug Administration. Firstly, the CPC powder and FG solution were mixed at different $\mathrm{P} / \mathrm{L}$ ratios $(\mathrm{g} / \mathrm{mL}): 5: 1,3: 1$, and $1: 1$ in sterile injection syringes. The mixture was then injected into a $6 \mathrm{~mm}$ (diameter) $\times 10 \mathrm{~mm}$ (height) cylinder mould. After being set in a humidor with $100 \%$ relative humidity at $37^{\circ} \mathrm{C}$ for 4 hours, the specimen was remolded. The same CPC powder mixed with water at the $\mathrm{P} / \mathrm{L}$ ratio of $3: 1(\mathrm{~g} / \mathrm{mL})$ was also prepared as a control. For the in vivo studies, the specimens were prepared under aseptic conditions 1 day before operations.

\section{SEM observation}

The composites were freeze-dried and coated with gold, and they were then examined under a $20 \mathrm{kV}$ scanning electron microscope (SEM; S-3000N; Hitachi, Ltd, Tokyo, Japan).

\section{Surgical procedure}

Sixty adult (1 1.5 years) male New Zealand White rabbits (provided by the Experimental Animal Center of the Fourth Military Medical University, Xi'an, Shaan, People's Republic of China), weighing from $2.8 \mathrm{~kg}$ to $3.5 \mathrm{~kg}$ (average weight, $3.0 \mathrm{~kg}$ ), were used in the study. The animal experiments were performed according to the protocols approved by the Institutional Animal Care Committee of the Fourth Military Medical University (permit number: 12014). At first, all the animals were randomly divided into four groups and each group had 15 animals. General anesthesia was induced by intramuscular injection of ketamine hydrochloride at a dose of $35 \mathrm{mg} / \mathrm{kg}$. All the rabbits were fastened onto a special plate in prone position to avoid any movement of their body during the operation. After shaving and disinfecting, the lateral longitudinal incision was performed in the bilateral femoral 
condyles of each animal. A cavity-like defect (diameter: $6 \mathrm{~mm}$, depth: $10 \mathrm{~mm}$ ) was made by a drill under abundant saline irrigation to avoid necrosis. The CPC-FG composite at different $\mathrm{P} / \mathrm{L}$ ratios $(1: 1,3: 1$, or $5: 1)$ or pure $\mathrm{CPC}$ was implanted into the cavity of each rabbit from the four groups. After implantation, the operative area was rinsed with saline and the incision was closed in layers. After the operation, the rabbits were treated with penicillin $(240,000 \mathrm{UI})$ for 3 days postoperatively.

Five animals from each group were sacrificed using an overdose of sodium pentobarbital at 4 weeks, 8 weeks, and 12 weeks after the operation. The material and surrounding bone tissue of the femoral condyles of each animal were harvested. The left femurs of each animal were used for biomechanical tests and were stored at $-20^{\circ} \mathrm{C}$ until use. The right femurs were used for micro-computed tomography (CT), and histological examinations were fixed in formaldehyde $(10 \%)$ for 3 5 days before application.

\section{Biomechanical testing}

The mechanical tests were performed after the soft tissue of the femoral condyles was removed. Every specimen was shaped into the $6 \mathrm{~mm}$ (diameter) $\times 10 \mathrm{~mm}$ (height) cylinder by a tubular drill (6 $\mathrm{mm}$ in diameter). Five specimens were tested from every group at 4 weeks, 8 weeks, and 12 weeks after implantation. The specimens without operation were tested at 0 weeks. Their diameters and lengths were precisely measured and recorded. The specimens were composed of the newly formed bone tissue and the residual materials. The mechanical properties of the specimens were analyzed by a materials testing machine (MTS-858; MTS Systems Corporation, Eden Prairie, MN, USA). An unconfined compression test was performed on hydrated scaffold samples at a deformation rate of $5 \mathrm{~mm} /$ minute until failure. We calculated the data with the following formulas:

$$
\begin{aligned}
\text { Compressive strength }(\mathrm{MPa})= & \text { Failure load } / \\
& \text { compression area }
\end{aligned}
$$

Elastic modulus $(\mathrm{GPa})=$ Stress $/$ deformation .

\section{Micro-CT analysis}

The specimens $(n=5)$ were examined by a micro-CT (eXplore Locus SP Pre-Clinical Specimen MicroCT; GE Healthcare Bio-Sciences Corp, Piscataway, NJ, USA) operated at a $14 \mu \mathrm{m}$ isotropic resolution to evaluate the new bone formation and the degradation of the materials. The threshold algorithm provided by the manufacturer of the micro-CT unit was applied to separate bone tissues from nonbony tissues.
The implanted cylinder, with a diameter of $6 \mathrm{~mm}$ and a height of $10 \mathrm{~mm}$, was chosen as the region of interest (ROI). The scanned slices were reconstructed in high solution to show the new bone formation and the degradation of the implants due to the different threshold for the bone and the material, which were analyzed by Microview software (GE Healthcare Bio-Sciences Corp). The residual material volume of residual fraction (RMVF) was calculated as the ratio between the volume of the residual material and the total volume of the materials within the ROI in each defect site, which could evaluate the degradation rate of the material. $\mathrm{RMVF}=$ bone volume per trabecular volume (VV/TV), in which VV is the volume of the residual material and TV is the total volume of the material. BV/TV was calculated, and the amount of the new bone formation into the cement was defined as the ROI, in which BV is the volume of the new bone formation and TV is the total volume of the implantation.

\section{Histological examination}

Following micro-CT scan, the specimens were dehydrated through a series of graded ethanol $(70 \%-100 \%)$. Then, the bones were subsequently cleared in toluene and embedded in methylmethacrylate without decalcification. Cross-sections with a thickness of approximately $200 \mu \mathrm{m}$ were cut from each specimen by a hard tissue microtome (Reichert-Jung Leica SP1600; Leica Microsystems, Wetzlar, Germany). Thereafter, the sections were polished into a thickness of 50-60 $\mu \mathrm{m}$ with an Exakt Grinder (EXAKT Advanced Technologies GmbH, Norderstedt, Germany). Finally, the slides were glued onto a plastic support, and stained with Van Geison stain for histological examination.

\section{Statistical analysis}

Statistical analysis was performed using the Statistical Package for the Social Sciences statistical software (SPSS, version 13.0; SPSS, Inc, Chicago, IL, USA). The data was presented as the mean \pm standard deviation, and levels were compared by a one-way analysis of variance and Student's $t$-test. $P$-values less than 0.05 were considered significant.

\section{Results}

\section{SEM observation}

Figure 1 displayed the images of the different $\mathrm{P} / \mathrm{L}$ ratios of CPC-FG and pure CPC samples, which were observed by SEM. The differences in the surface morphology of CPC and FG behaved differently. FG presented with a relatively denser and smoother structure compared with CPC. In the pure CPC group, the morphology of a rough surface on the 


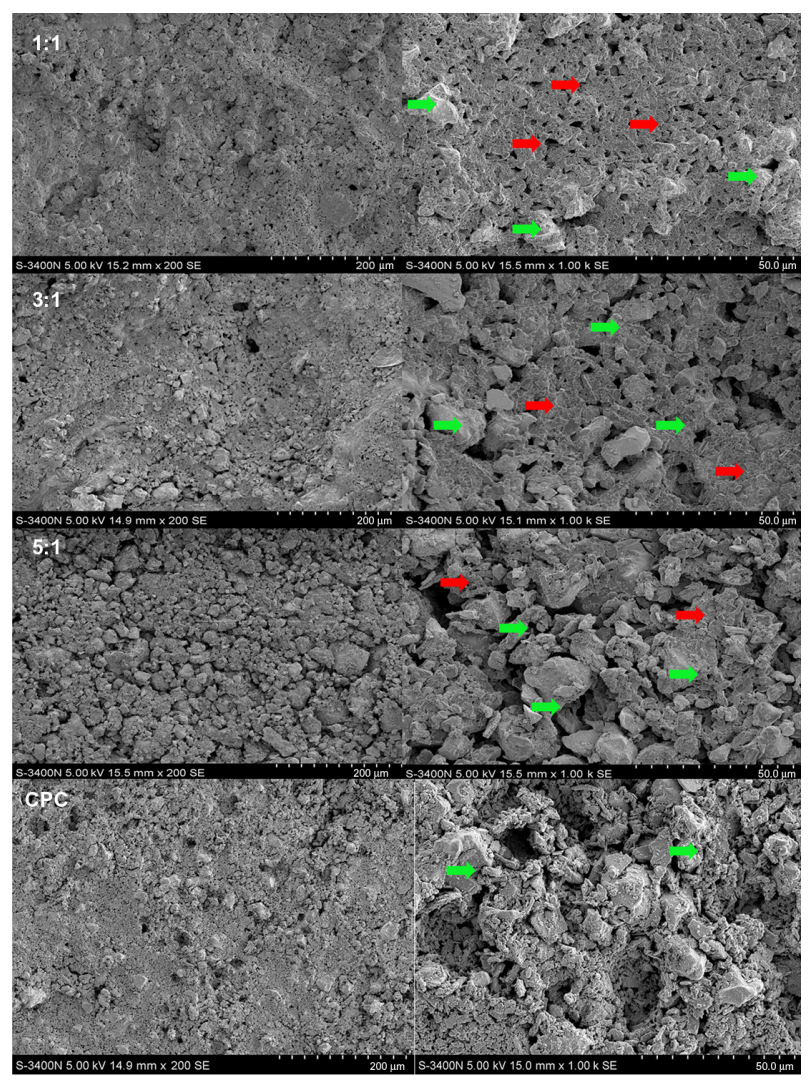

Figure I SEM images of the CPC-FG composites at different $P / L$ ratio and the pure CPC fresh prepared.

Notes: Red arrow: FG; green arrow: CPC.

Abbreviations: SEM, scanning electron microscope; CPC, calcium phosphate cement; FG, fibrin glue; P/L, powder/liquid.

samples was always evident. As the FG content increased from a 5:1 $\mathrm{P} / \mathrm{L}$ ratio to a $1: 1 \mathrm{P} / \mathrm{L}$ ratio, the samples showed more contact between the CPC particles and the gel FG, and the round pores of the cements became smaller and closer.

\section{Biomechanical testing}

The results of the compressive strength were plotted in Figure $2(n=5)$. The compressive strength of each $\mathrm{CPC}-\mathrm{FG}$ group was much higher than that of the pure $\mathrm{CPC}$ group, what-
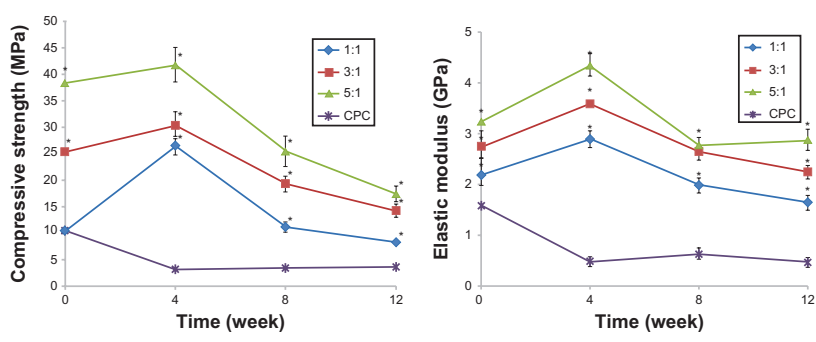

Figure 2 Compressive strength and the elastic modulus $(n=5)$.

Note: *Significance at $P<0.05$

Abbreviations: $n$, number; $\mathrm{MPa}$, compressive strength; $\mathrm{GPa}$, elastic modulus. ever the implantation period $(P<0.05)$. Compressive strength of the pure CPC decreased after implantation from week 4 to week 12. The compressive strength of the pure CPC at the different implantation periods of 4 weeks, 8 weeks, and 12 weeks remained lower than the data observed before implantation. However, the compressive strength of the three ratios of CPC-FG all increased at week 4 after the operation, and decreased from week 8 to week 12. The compressive strength of CPC-FG at the P/L ratio of $5: 1(\mathrm{~g} / \mathrm{mL})$ was highest at any determined time in the four groups.

Figure 2 also shows the results of the elastic modulus studies. The elastic modulus of the CPC group was much lower than that of any CPC-FG group at each time point $(P<0.05)$. The results of the CPC-FG groups at ratios of $1: 1,3: 1$, and 5:1 all increased at 4 weeks after implantation, and decreased at 8 weeks and 12 weeks after implantation.

\section{Micro-CT analysis}

After 4 weeks, the newly formed bone showed little direct contact with the cement in all the four groups. The 1:1 group showed a slightly greater amount of newly formed bone in the peripheral portion of the cement than any other group (Figure 3). Eight weeks later, the zone in which the bone made contact with the cement increased due to the new bone formation. At the same time, the cylinder of cement had been partly absorbed and replaced by newly formed bone trabeculae in the periphery. The 1:1 group showed the largest new bone formation at both the peripheral and central areas of the cement (Figure 4). After 12 weeks, the degradation of the materials continued, and the bone regeneration continued at the same time. The 1:1 group also showed the fastest degradation of the material and the best new bone formation in the four groups (Figure 5). The data in Figure 6 supported the images observed during micro-CT. The RMVF of the 1:1 group was lowest at any determined time

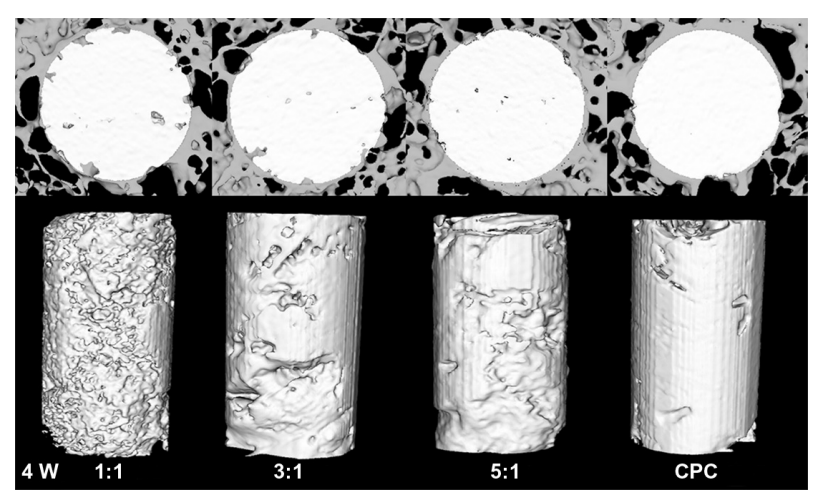

Figure 3 Reconstruction the cross section images of rabbit femur and residual material of the composite by micro-CT analysis at 4 weeks after the operation. Abbreviations: $\mathrm{CT}$, computed tomography; CPC, calcium phosphate cement. 


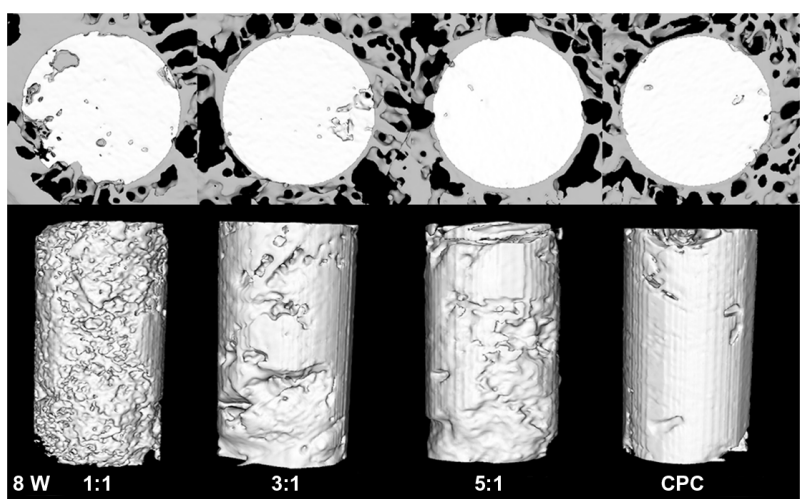

Figure 4 Reconstruction of the cross-sectional images of rabbit femur and residual material of the composite by micro-CT analysis at 8 weeks after the operation. Abbreviations: CT, computed tomography; CPC, calcium phosphate cement.

after the operation, which was $87.01 \% \pm 1.96 \%$ at 4 weeks, $76.90 \% \pm 2.34 \%$ at 8 weeks, and $63.21 \% \pm 2.89 \%$ at 12 weeks, respectively. The BV/TV of 1:1 group was the highest in the four groups, which was $1.45 \% \pm 0.42 \%, 7.35 \% \pm 1.45 \%$, and $29.10 \% \pm 1.67 \%$ at 4 weeks, 8 weeks, and 12 weeks after the operation, respectively.

\section{Histological examination}

The bone, cartilage, fibrous tissue, and residual material were stained into red, purple, blue, and black colors, respectively, by Van Geison staining. After 4 weeks of implantation, the bone growth in the composite was hardly observed in all groups. In the 1:1 group, the peripheral layer around the material had stained purple, where the new bone growth was apparent in the cartilage. In the 3:1 group, the cartilage could also be observed, which was not as evident as it was in the 1:1 group. There was no obvious indication of osteogenesis in the 5:1 group and the CPC group (Figure 7).

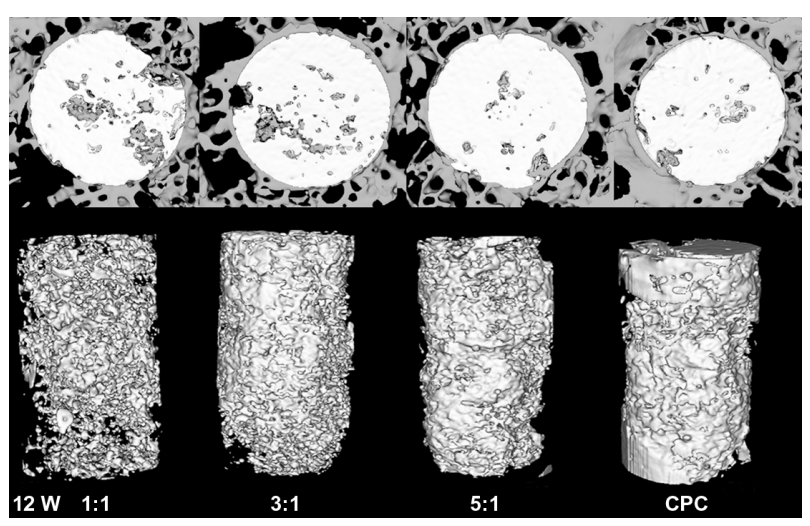

Figure 5 Reconstruction of the cross-sectional images of rabbit femur and residual material of the composite by micro-CT analysis at 12 weeks after the operation. Abbreviations: CT, computed tomography; CPC, calcium phosphate cement.

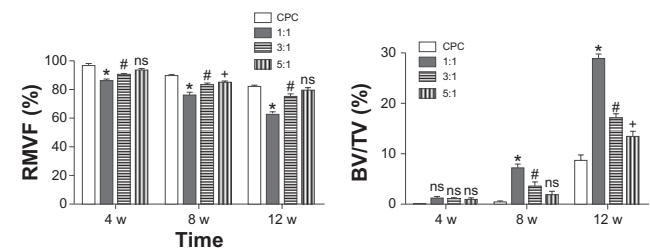

Figure 6 Results of RMVF and BV/TV from micro-CT analysis $(n=5)$.

Notes: RMVF evaluated the degradation of the material; BV/TV evaluated the new bone formation. The CPC group was the control group. *The significance between the I:I group and the CPC group $(P<0.05)$; "the significance between the I:I group and the CPC group $(P<0.05)$. The symbol "ns" represented the significance between the I:I group and the CPC group $(P<0.05)$.

Abbreviations: RMVF, residual material volume fraction; $\mathrm{BV}$, bone volume; TV, trabecular (total) volume; CT, computed tomography; n, number; CPC, calcium phosphate cement.

With the increase of the implantation period of up to 8 weeks, the bone was deposited directly onto the implant surface and connected tightly in both the 1:1 and 3:1 groups. In the 5:1 group and the CPC group, the conjunction between the bone tissue and the cement was not as tight as that in the 1:1 group and the 3:1 group (Figure 8).

Further increasing the implantation period to 12 weeks, the bone in the 1:1 group grew into the pore of cement and appeared to be in the laminar arrangement. The material showed a good osseointegration effect with the bone tissue. In contrast, in the $3: 1,5: 1$, and CPC groups, the interface between the bone and materials were not as tight as observed in the 1:1 group, and the implanted cement was not as obviously substituted by bone tissue as was found in the 1:1 group (Figure 9). Inflammatory cells or acute inflammation processes were not observed in any of the groups.

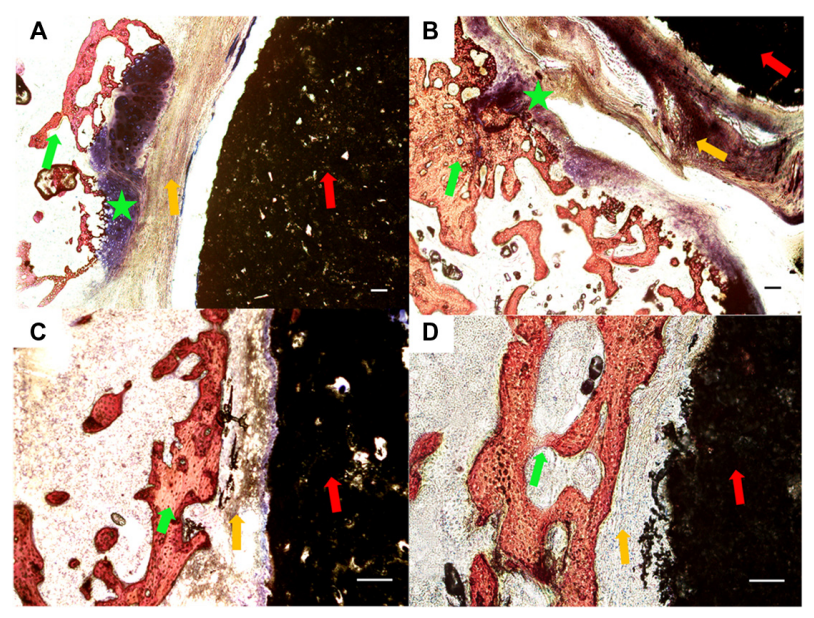

Figure 7 Histological morphologies after implantation at 4 weeks. (A) The I:I P/L ratio of CPC-FG; (B) 3:I P/L ratio of CPC-FG; (C) 5:I P/L ratio of CPC-FG; (D) pure CPC.

Notes: The green star indicates cartilage; the red arrow represents materials; the yellow arrow indicates fibrous tissue; and the green arrow represents bone. Bars $=100 \mu \mathrm{m}$.

Abbreviations: CPC, calcium phosphate cement; FG, fibrin glue; P/L, powder/liquid. 


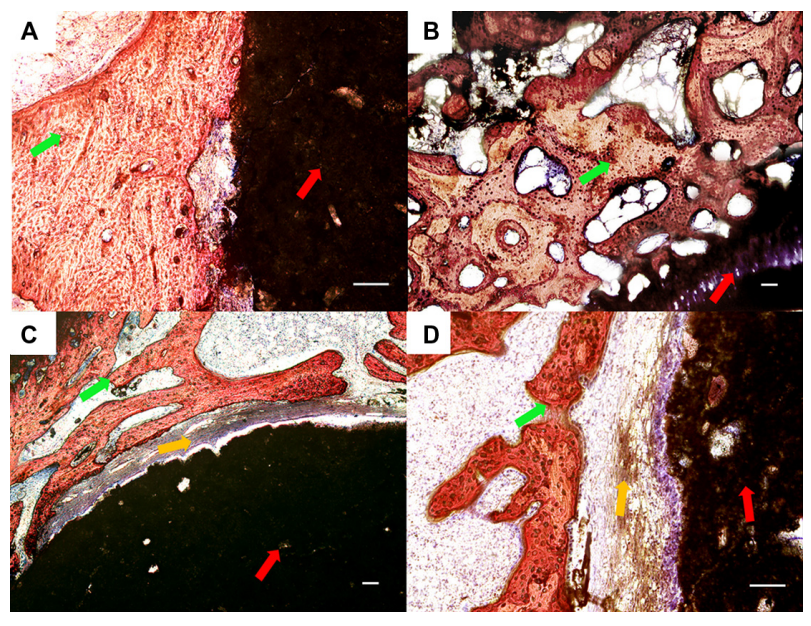

Figure 8 Histological morphologies after implantation at 8 weeks. (A) The I:I P/L ratio of CPC-FG; (B) 3:I P/L ratio of CPC-FG; (C) 5:I P/L ratio of CPC-FG; (D) pure CPC.

\section{Discussion}

In this study, three different ratios of $\mathrm{CPC}-\mathrm{FG}$ and pure CPC were investigated histologically and biomechanically after they were implanted in rabbit femoral defects. The CPC-FG group at the ratio of $1: 1(\mathrm{~g} / \mathrm{mL})$ exhibited the best bone formation and interface conjunction in the micro-CT analysis and histological analysis at 4 weeks, 8 weeks, and 12 weeks after implantation in the four groups. The compressive strength and the elastic modulus of each CPC-FG group were both higher than those of the pure CPC group, whatever the implantation period $(P<0.05)$.

Nowadays, CPC is the good osteoinductive and osteoconductive material known by material scientists and is widely used in bone tissue engineering. However, the poor mechanical property of CPC has limited its application into the nonload-bearing condition. ${ }^{17,18}$ From this biomechanical

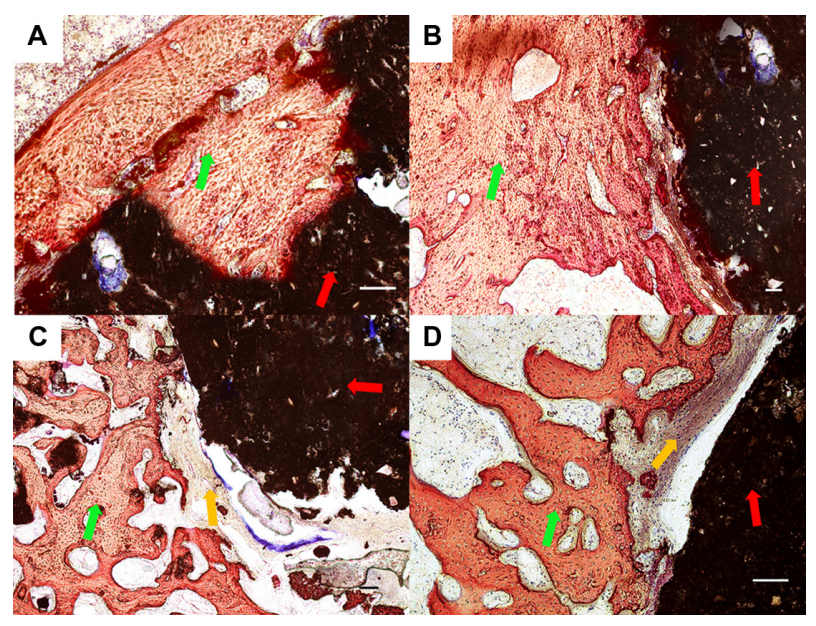

Figure 9 Histological morphologies after implantation at 12 weeks. (A) The I:I P/L ratio of CPC-FG; (B) 3:I P/L ratio of CPC-FG; (C) 5:I P/L ratio of CPC-FG; (D) pure CPC. testing in vivo, it is easy to find that the compressive strength and the elastic modulus of each CPC-FG group was higher than those of the pure CPC group, whatever the implantation period. It seemed that $\mathrm{FG}$ effectively enhanced the mechanical properties of CPC. The incorporation of polymers into CPC has been a well known strategy over the mechanical limitations. By adding polymers including gelatin, chitosan, and collagen in either the powder phase or the liquid phase, the mechanical property, biocompatibility, and bioactivity of CPC all improved. ${ }^{19-21}$ In this study, the pure CPC relied solely on the apatite crystals in order to interlock to provide strength. FG was well distributed in the CPC-FG composite by the SEM observation of this study. The CPC-FG composites not only had interlocking crystals, but it also had additional FG, which could bind the apatite crystals together. Some material scientists also reported that porosity, pore size, and pore size distribution increased by adding higher volumes of FG into CPC. ${ }^{22}$ The porosity, pore size, and pore size distribution could affect the biomechanical properties of the materials. This could be the reason why the compressive strength of the 5:1 group was the highest in the four groups. Some material scientists reported that the CPC-FG composite showed signs of transformation and growth of the crystalline phase of the CPC particles after being immersed in Ringer's solution for 3 days, due to the polymerization of fibrinogen and thrombin. ${ }^{22}$ As the interfacial bonding between $\mathrm{CPC}$ and FG increased, the compressive strength and the elastic modulus of each $\mathrm{CPC}-\mathrm{FG}$ group increased in the early stage in vivo. Owing to the degradation of FG in vivo, the mechanical properties decreased at a later stage. It was concluded that the cross-linking of CPC and FG, the degradation of the material, and the maturation of the bone together resulted in this dynamic tendency.

Previous research has shown that CPC performed the different tissue reactions in cortical bone, cancellous bone, and medullar bone; ${ }^{23}$ the best bone regeneration was observed in cortical bone, the medullar bone was the worst. The material biodegradation was the highest in the medullar bone, and the cortical bone was the lowest. To evaluate the functionality of the biomaterial, the cancellous bone is the suitable site. ${ }^{23}$ Some researchers reported that the compressive strength of the cancellous bone is about $3.75 \mathrm{MPa}$, and the elastic modulus of the cancellous bone is about $1.75 \mathrm{GPa} .{ }^{24} \mathrm{In}$ this study, the compressive strength and the elastic modulus of the CPC-FG specimens at the P/L ratio of $1: 1(\mathrm{~g} / \mathrm{mL})$ were the closest to those of cancellous bone in the four groups. In this study, the surgical area was the femoral condyle of the rabbit, and the implanted material was surrounded by the cancellous bone in vivo. The hypothesis was that the CPC-FG cement at 
the ratio of $1: 1(\mathrm{~g} / \mathrm{mL})$ had similar mechanical properties as the surrounding bone. In this system, the surrounding bone could get adequate mechanical stimulation, which could induce new bone formation.

The results in this study demonstrated not only good mechanical compatibility, but also good biocompatibility of $\mathrm{CPC}-\mathrm{FG}$ at the $\mathrm{P} / \mathrm{L}$ ratio of $1: 1(\mathrm{~g} / \mathrm{mL})$. The micro-CT analysis and the histological analysis both showed that the CPC-FG at the P/L ratio of $1: 1(\mathrm{~g} / \mathrm{mL})$ resulted in better bone formation and interface conjunction than any other group. It was considered that the pore size of the cement could be one reason for this result. CPC is a family of materials that includes self-setting HA and brushite, which is the main component in bone matrix, and which is obtained by soft chemistry routes. ${ }^{25} \mathrm{CPC}$ powders are intrinsically porous materials. Moreover, CPC possesses micro- or nanometer range pores, but it lacks macropores, which are essential structures for tissue colonization. The bone tissue grows on the surface of CPC and is unable to penetrate inside the material due to the small size of the pores.

CPC has a low degradation rate, which remained more than 78 weeks after being implanted into the dog femur. ${ }^{26}$ Some scientists also reported that the degradation rate of the FG is approximately $10-14$ days. ${ }^{27}$ The degradation rate of the CPC-FG should be in line with the degradation rate of FG. FG in CPC-FG degraded in vivo, which was helpful for the material to form the macroporous structure. FG has been used as a hemostatic agent and a sealant for decades. ${ }^{28,29}$ It has two components: fibrinogen and thrombin. When the two components are mixed, the thrombin activates the fibrinogen to form the fibrin clot. In this study, three $\mathrm{P} / \mathrm{L}$ ratios of $\mathrm{CPC}-\mathrm{FG}$ equaled three different ratios of thrombin concentrations and three different ratios of ionic strength of the solution. Some researchers reported that the cement pore size and the fiber diameter were dependent on cross-linking time, which changed in accordance with the thrombin concentration or the ionic strength of the solution. ${ }^{30}$ The pore size and the fiber diameter affected both the structure and degradation of the gel. The degradation of the material and the regeneration of new bone could have the dynamic balance to make the optimal bone regeneration. From the micro-CT analysis (Figure 5), it was easily found that the degradation of the material was earlier than the regeneration of the new bone. It indirectly demonstrated that the degradation of the material changed the pore size of the implanted cement, which affected new bone regeneration. It was possible that $\mathrm{CPC}-\mathrm{FG}$ at the $\mathrm{P} / \mathrm{L}$ ratio of $1: 1(\mathrm{~g} / \mathrm{mL})$ may form the pore size suitable to achieve a dynamic balance for cement degradation and the bone regeneration.
$\mathrm{CPC}$ is a kind of material that has good biocompatibility; however, it generally has low cell attachment and low proliferation rates in cell cultures in vitro. Our previous in vitro study demonstrated that the CPC-FG scaffold could support bone marrow stromal stem cell attachment and proliferation, equal to that of the $\mathrm{CPC}$ control, and no obvious difference existed between $\mathrm{CPC}-\mathrm{FG}$ and pure $\mathrm{CPC} ;{ }^{31}$ however, in this in vivo study, a different situation was shown. The CPC-FG composite had a better effect on bone formation than the CPC control. It was possible that the environment of the cell was also a problem. The cell culture was a closed and static system in vitro, which was different from the study in vivo. Several researchers reported that FG was a reservoir for several growth factors during the in vivo degradation, such as for vascular endothelial growth factor, ${ }^{32}$ basic fibroblastic growth factor, ${ }^{33}$ transforming growth factor-B $1,{ }^{34}$ and growth factor-binding proteins such as insulin-like growth factorbinding protein-3 for insulin-like growth factor. ${ }^{35}$ These factors could change the cell culture in vivo.

\section{Conclusion}

The introduction of FG into CPC can improve the mechanical strength and osteoinductivity of CPC. The in vivo experiments indicated that the $\mathrm{CPC}-\mathrm{FG}$ composition at the $\mathrm{P} / \mathrm{L}$ ratio of 1:1 showed the best effects for enhancing new bone formation and for improving the mechanical properties of the operation areas. The findings may help surgeons find a good additive and an optimal $\mathrm{P} / \mathrm{L}$ ratio in the application of $\mathrm{CPC}$. Further studies are necessary to investigate the mechanism of osteogenesis induced by the CPC-FG composite. First, the in vivo osteoinductive effect of the FG in the $\mathrm{CPC}$ needs to be clarified. Second, $\mathrm{CPC}-\mathrm{FG}$ directly injected into the defect should be added to compare osteogenesis when it was implanted into the defect. And third, mechanical properties of $\mathrm{CPC}-\mathrm{FG}$ need to be studied to find its relationship with new bone formation.

\section{Acknowledgments}

This study was supported by the National Natural Science Foundation of China (81000790) and the Science and Technology New Star Foundation of Beijing (031507).

\section{Disclosure}

The authors report no conflicts of interest in this work.

\section{References}

1. Banwart JC, Asher MA, Hassanein RS. Iliac crest bone graft harvest donor site morbidity. A statistical evaluation. Spine (Phila Pa 1976). 1995;20(9):1055-1060. 
2. Silber JS, Anderson DG, Daffner SD, et al. Donor site morbidity after anterior iliac crest bone harvest for single-level anterior cervical discectomy and fusion. Spine (Phila Pa 1976). 2003;28(2):134-139.

3. Younger EM, Chapman MW. Morbidity at bone graft donor sites. J Orthop Trauma. 1989;3(3):192-195.

4. Friedlaender GE, Strong DM, Tomford WW, Mankin HJ. Long-term follow-up of patients with osteochondral allografts. A correlation between immunologic responses and clinical outcome. Orthop Clin North Am. 1999;30(4):583-588.

5. Klijn RJ, Meijer GJ, Bronkhorst EM, Jansen JA. A meta-analysis of histomorphometric results and graft healing time of various biomaterials compared to autologous bone used as sinus floor augmentation material in humans. Tissue Eng Part B Rev. 2010;16(5):493-507.

6. Nkenke E, Stelzle F. Clinical outcomes of sinus floor augmentation for implant placement using autogenous bone or bone substitutes: a systematic review. Clin Oral Implants Res. 2009;20 Suppl 4:124-133.

7. Wang S, Zhang Z, Zhao J, et al. Vertical alveolar ridge augmentation with beta-tricalcium phosphate and autologous osteoblasts in canine mandible. Biomaterials. 2009;30(13):2489-2498.

8. Tessmar JK, Göpferich AM. Matrices and scaffolds for protein delivery in tissue engineering. Adv Drug Deliv Rev. 2007;59(4-5):274-291.

9. Chow LC, Brown WE. A physico chemical bench-scale caries model. J Dent Res. 1984;63:868-873.

10. Liu H, Li H, Cheng W, Yang Y, Zhu M, Zhou C. Novel injectable calcium phosphate/chitosan composites for bone substitute materials. Acta Biomater. 2006;2(5):557-565.

11. Xu HH, Simon CG Jr. Fast setting calcium phosphate-chitosan scaffold: mechanical properties and biocompatibility. Biomaterials. 2005;26(12): 1337-1348

12. Mickiewicz RA, Mayes AM, Knaack D. Polymer - calcium phosphate cement composites for bone substitutes. J Biomed Mater Res. 2002;61(4):581-592.

13. Abiraman S, Varma HK, Umashankar P, John A. Fibrin glue as an osteoinductive protein in a mouse model. Biomaterials. 2002;23(14): 3023-3031.

14. Greco F, de Palma L, Specchia N, Lisai P. Experimental investigation into reparative osteogenesis with fibrin adhesive. Arch Orthop Trauma Surg. 1988;107(2):99-104.

15. Oberg S, Kahnberg KE. Combined use of hydroxy-apatite and Tisseel in experimental bone defects in the rabbit. Swed Dent J. 1993;17(4): $147-153$.

16. Meenach SA, Vogt FG, Anderson KW, Hilt JZ, McGarry RC, Mansour HM. Design, physicochemical characterization, and optimization of organic solution advanced spray-dried inhalable dipalmitoylphatidylcholine (DPPC) and dipalmitoylphosphatidylethanolamine poly(ethylene glycol) (DPPE-PEG) microparticles and nanoparticles for targeted respiratory nanomedicine delivery as dry powder inhalation aerosols. Int J Nanomedicine. 2013;8:275-293.

17. Barinov SM, Komlev VS. Calcium phosphate bone cements. Inorganic Materials. 2011;47(13):1470-1485.

18. Hirano M. Calcium phosphate bone cement. Ceram Jap. 2003;38: 47-50.
19. Perez RA, Del Valle S, Altankov G, Ginebra MP. Porous hydroxyapatite and gelatin/hydroxyapatite microspheres obtained by calcium phosphate cement emulsion. J Biomed Mater Res B Appl Biomater. 2011;97(1):156-166.

20. Moreau JL, Weir MD, Xu HH. Self-setting collagen-calcium phosphate bone cement: mechanical and cellular properties. J Biomed Mater Res A. 2009;91(2):605-613.

21. Wang X, Ma J, Wang Y, He B. Structural characterization of phosphorylated chitosan and their applications as effective additives of calcium phosphate cements. Biomaterials. 2001;22(16):2247-2255.

22. Loper-Heredia MA, Pattipeilohy J, Hsu S, et al. Bulk physicochemical, interconnectivity, and mechanical properties of calcium phosphate cements-fibrin glue composites for bone substitute applications. J Biomed Mater Res A. 2013;101(2):478-490.

23. Lu JX, Gallur A, Flautre B, et al. Comparative study of tissue reactions to calcium phosphate ceramics among cancellous, cortical, and medullar bone sites in rabbits. J Biomed Mater Res. 1998;42(3):357-367.

24. Lu JX, About I, Stephan G, et al. Histological and biomechanical studies of two bone colonizable cements in rabbits. Bone. 1999; 25(Suppl 2):41S-45S.

25. Dorozhkin SV. Calcium orthophosphates. Journal of Materials Science. 2007;42:1061-1095.

26. Apelt D, Theiss F, El-Warrak AO, et al. In vivo behavior of three different injectable hydraulic calcium phosphate cements. Biomaterials. 2004;25(7-8):1439-1451.

27. Juhan-Vague I, Hans M. From fibrinogen to fibrin and its dissolution. Bull Acad Natl Med. 2003;187(1):69-82; discussion 83-84. French.

28. Radosevich M, Goubran H, Burnouf T. Fibrin sealant: scientific rationale, production methods, properties, and current clinical use. Vox Sang. 1997;72(3):133-143.

29. Silver FH, Wang MC, Pins GD. Preparation and use of fibrin glue in surgery. Biomaterials. 1995;16(12):891-903.

30. Sierra DH. Fibrin sealant adhesive systems: a review of their chemistry, material properties and clinical applications. J Biomater Appl. 1993;7(4):309-352.

31. Cui G, Li J, Lei W, et al. The mechanical and biological properties of an injectable calcium phosphate cement-fibrin glue composite for bone regeneration. J Biomed Mater Res B Appl Biomater. 2010;92(2): 377-385.

32. Sahni A, Francis CW. Vascular endothelial growth factor binds to fibrinogen and fibrin and stimulates endothelial cell proliferation. Blood. 2000;96(12):3772-3778.

33. Sahni A, Odrljin T, Francis CW. Binding of basic fibroblast growth factor to fibrinogen and fibrin. J Biol Chem. 1998;273(13):7554-7559.

34. Catelas I, Dwyer JF, Helgerson S. Controlled release of bioactive transforming growth factor beta-1 from fibrin gels in vitro. Tissue Eng Part C Methods. 2008;14(2):119-128.

35. Campbell PG, Durham SK, Hayes JD, Suwanichkul A, Powell DR. Insulin-like growth factor-binding protein-3 binds fibrinogen and fibrin. J Biol Chem. 1999;274(42):30215-30221.
International Journal of Nanomedicine

\section{Publish your work in this journal}

The International Journal of Nanomedicine is an international, peerreviewed journal focusing on the application of nanotechnology in diagnostics, therapeutics, and drug delivery systems throughout the biomedical field. This journal is indexed on PubMed Central, MedLine, CAS, SciSearch ${ }^{\circledR}$, Current Contents ${ }^{\circledR} /$ Clinical Medicine,
Dovepress

Journal Citation Reports/Science Edition, EMBase, Scopus and the Elsevier Bibliographic databases. The manuscript management system is completely online and includes a very quick and fair peer-review system, which is all easy to use. Visit http://www.dovepress.com/ testimonials.php to read real quotes from published authors. 